\title{
Natural Disasters : A Comparison of Alternative Methods for Evaluating Preventive Measures
}

\author{
by M. W. Jones-Lee*
}

The primary purpose of the Working Group is " ... to investigate and define the role of disaster insurance in reducing disaster risks through financial transfers and stimulation of preventive measures". This paper is concerned with the criteria by which different preventive measures might be compared and evaluated, particularly when such measures can be expected to have effects upon the safety of human life.

Potential measures for preventing natural disasters, or for mitigating their adverse consequences, are numerous and varied. Engineers, scientists and doctors could no doubt suggest any number of schemes and contingency arrangements which would reduce the risk of occurrence of particular kinds of disaster or, in the case of inherently unavoidable events such as earthquakes, would attenuate the scale of injury and damage associated with the disaster. Such preventive measures will, however, usually involve substantial resource costs and given the inescapable fact of resource scarcity, choices will necessarily have to be made amongst competing preventive options. Put simply, budget constraints will dictate that it will not be feasible to effect every possible preventive measure for all conceivable kinds of disaster.

In this respect, the evaluation of preventive measures for natural disasters is in principle no different from the evaluation of any set of options for reducing risks of death, injury and material damage (e.g. road safety measures or public health programmes). In the case of natural disasters, however, the problems are probably more acute and their systematic resolution therefore all the more important for the very simple reason that the adverse consequences of such disasters are usually on a far larger scale than in the case of, say, the typical motor vehicle accident or domestic fire. Given the likely extent of death, injury and material damage from earthquakes, floods, famine and so on it is particularly desirable that such resources as are made available for preventing or reducing the adverse consequences of disasters should be deployed as efficiently as possible, with limited resources and funds being directed to their most effective use.

All this suggests that in the case of natural disasters it is especially important to develop rational, systematic procedures for deciding how scarce resources are to be

* Department of Economics, University of Newcastle upon Tyne, Newcastle upon Tyne, NE1 7RU, England. 
allocated amongst competing preventive measures. In general terms, systematic evaluation of preventive measures would seem to involve two fundamental prerequisites :

(a) estimates of the likely effects of alternative preventive measures (these might take the form of estimates of the reduction in probability of occurrence of particular types of disaster as a result of the adoption of specific preventive measures, or predictions concerning the impact of such measures in reducing the number of fatalities and injuries and the extent of material damage due to the disaster), and

(b) a decision criterion or procedure which will allow the various effects estimated in (a) to be weighed in relation to the resource cost of each potential preventive measure in order to decide whether or not the measure should be undertaken.

These two aspects of the evaluation of preventive options are, of course, highly interdependent. Estimates of likely effects, however detailed and accurate, will be of little real use for evaluative purposes in the absence of a decision criterion for assessing the "worth" of such effects and for comparing the different effects of competing schemes, while a well-specified decision criterion is equally ineffective without the requisite input data concerning the expected effects of different measures. Nonetheless, in spite of this ultimate interdependence in use, the two aspects are clearly conceptually separable and indeed probably most effectively dealt with as distinct problem areas, at least at the level of principle. Since estimation of the effects of different preventive measures is an essentially technical and/or medical matter, this paper will concentrate upon the question of decision criteria for the selection of preventive measures on the assumption that estimates of likely effects have already been obtained by whatever means. ${ }^{1}$

\section{The problem of diversity of effects}

Were it the case that different preventive measures could all be expected to generate precisely the same kind of effect, albeit in differing degrees, then matters would be relatively straightforward. If, for example, the sole adverse impact of natural disasters was loss of human life (so that preventive measures simply reduced the number of lives lost) then it would seem appropriate to allocate scarce preventive resources amongst competing schemes so as to minimise lives lost, at least within a given country or region.

But of course preventive measures will typically have a number of different effects, amongst the more inportant of which will be reduction in loss of life, reduction of injury and suffering and reduction of material damage. ${ }^{2}$ Furthermore the "mix " of such effects will tend to vary between different preventive measures. An effective decision criterion will have to provide a means of weighing and "aggregating" such effects if the selection of preventive measures is to proceed on a rational basis.

1 The reader should be warned that this assumption begs a number of very important questions. For example, how are risk effects to be estimated and by whom? If the estimation is to be done by " experts", how reliable can such estimates be expected to be and subject to what kinds of bias? To what extent should account be taken of the public's perception (or more accurately in many cases, misperception) of risk? There is a large and growing literature concerned with these and other questions but a useful summary is given in Slovic, Fischhoff and Lichtenstein [1980].

${ }^{2}$ For a more detailed discussion of the possible effects of natural disasters, see United Nations [1979]. 
The weighing and aggregation of diverse material damage effects presents little difficulty, at least in principle. The straightforward application of standard techniques of cost-benefit analysis would provide a single monetary measure of the expected benefit from a reduction in the risk of damage to houses, vehicles, capital equipment and arable land owing to the implementation of a particular preventive measure. To be sure, one would encounter all the usual problems of shadow pricing, discounting and distributional effects associated with cost-benefit analysis, ${ }^{3}$ but the material damage effects of natural disasters present no new problems of principle. When we turn to effects on health and the safety of human life, however, matters are rather more complicated. In the first place there is still no consensus amongst economists, decision theorists and decision makers concerning the appropriate means by which to handle safety effects in project appraisal. ${ }^{4}$ Second, the sheer scale of such effects in natural disasters presents added problems. For example, is it appropriate to apply the same kind of decision criterion to (possibly large) reductions in the risk of large loss of life as might be applied in the analysis of small reductions in the risk of loss of relatively few lives (e.g. in the evaluation of the typical road-safety improvement scheme) ? In the remainder of this paper I shall examine the various different procedures that have been proposed for taking account of safety effects in project appraisal with a view to establishing which, if any, of these procedures might be appropriate for the special case of the evaluation of preventive measures for natural disasters.

\section{Possible procedures for taking account of safety effects in project appraisal}

Suppose that a decision maker must select one from a number of mutually exclusive projects or programmes each of which has some expected effect on the safety of human life. Notice that the "Accept/reject" decision for a given project is simply the special case in which the options are just two, namely " accept project" and " maintain status quo". Suppose in addition that the safety-effects of the various projects have already been estimated. What use is the planner to make of such estimates? There would appear to be just six reasonably sensible approaches open to him.

(i) To ignore the estimates on the grounds that there is no obviously " right "way to evaluate safety-effects or to compare such effects between projects. Some people even go so far as to argue that it is morally repugnant to attempt an explicit evaluation of the safety of human life.

(ii) Not to ignore the estimates, but equally not to attempt any kind of explicit evaluation, relying instead upon an informal weighing of such effects based upon " educated good sense" and judgement. This informal judgement might either be that of the decision maker himself, or, alternatively, of the relevant politician or government department.

(iii) To use safety standards or targets. Under this approach, sources of potential disaster would be identified and priority would then be given to high risk areas (i.e. relatively high probabilities of large loss of life and extensive injury), the ultimate aim being to bring all risks down to some predetermined "acceptable" level.

3 For a discussion of some of these problems see Layard [1972] or Sugden and Williams [1978].

4 For a discussion of some of the central issues in this debate, see Jones-Lee [1982]. 
(iv) To use some form of cost-effectiveness analysis. Basically, cost-effectiveness analysis attempts to maximise the extent of achievement of a particular desirable goal or objective within a pre-specified budget or, equivalently, to minimise the expenditure needed to achieve a pre-specified goal.

(v) To evolve criteria for assigning explicit (monetary) costs to accidents and explicit (monetary) values to their avoidance so that safety effects can be incorporated directly into standard procedures of project appraisal.

(vi) To employ a decision analysis approach. This would involve an identification of the decision maker's key objectives and priorities and the subsequent estimation of the structure and parameters of a so-called "multi-attribute utility function" for the decision maker. The primary purpose of this approach is not so much to turn decision making into a mechanical procedure, as to facilitate decisions concerning complex issues by providing the decision maker with an ordered structure and framework within which to assemble and evaluate a wide diversity of information.

In subsequent sections it will be argued that if the primary consideration in the evaluation of preventive measures is to ensure an economically efficient ${ }^{s}$ allocation of scarce preventive resources then only the fifth and sixth of the above approaches offer a significant prospect of achieving such efficiency. This, together with other considerations that are likely to be regarded as important factors in evaluation (such as a desire for the equitable treatment of different groups or concern to avoid catastrophes per se), suggests that explicit values of avoidance of loss of life and injury employed within one of the simpler and more straightforward versions of decision analysis would probably provide the most effective means of evaluating different preventive options in the case of natural disasters. The conclusion, then, is that a "blend" of the fifth and sixth approaches will probably be called for. Development of the case in support of this conclusion must begin with a detailed analysis and assessment of the six approaches.

\section{The "No Analysis" approach}

If safety effects are simply ignored in the evaluation of preventive measures then, to the extent that such effects are beneficial, they will tend to be under provided and, if harmful, over provided. In short, if any significant components of benefit or cost are ignored in the evaluation procedure then this will almost inevitably result in an inefficient and suboptimal allocation of scarce resources. This assertion would be qualified only if randomness in the allocation of resources was held to be desirable per se, or if the resource cost of analysing the effects was itself prohibitive in relation to their potential impact. Neither of these possibilities would seem to have much relevance to the analysis of preventive measures for natural disasters.

${ }^{5}$ An allocation of resources (and accompanying distribution of commodities) is said to be economically efficient if (a) no alternative allocation of productive resources would lead to an increase in the output of some commodity (or desirable end) without reducing the output of some other commodity(ies) and (b) no alternative distribution of commodities would increase the well-being of some individual without reducing that of some other individual(s). 


\section{The "Informal Judgement" approach}

The second approach - to rely upon the informal judgement of the project planner or relevant politician - appears at first sight to have much to commend it. Clearly this approach avoids the pitfalls of simply ignoring safety effects while at the same time sidestepping the difficult and contentious problem of developing methods of explicit evaluation. Unfortunately, this approach also suffers from serious potential limitations as a means of achieving allocative efficiency. Simply put, leaving the assessment of safety effects to informal judgement will almost certainly lead to substantial inconsistency in the treatment of such effects both between different planners and by a given planner in relation to different preventive measures. The problem of inconsistency can be highlighted by introducing the concept of an "implicit value of accident avoidance" or, more graphically, an "implicit value of life". Suppose that a planner must choose one of two alternative preventive measures which, for simplicity, we take to have identical capital costs but which differ in their anticipated effects on accident rates and material damage. Specifically, suppose that the preventive measures have the following characteristics:

$\begin{array}{lccc}\text { Capital Cost } & \begin{array}{c}\text { Expected Reduction } \\ \text { in Damage Costs }\end{array} & \begin{array}{c}\text { Expected Reduction } \\ \text { in Number of Fatalities }\end{array} \\ \text { Measure A } & \$ 400,000 & \$ 450,000 & 1 \\ \text { Measure B } & \$ 400,000 & \$ 150,000 & 4\end{array}$

A project planner who opts for Measure A clearly reveals an implicit value of life of less than $\$ 100,000$ simply because, by rejecting $\mathrm{B}$ in favour of $\mathrm{A}$, he implicitly indicates that the additional 3 lives saved under B are "not worth" the loss of $\$ 300,000$ damage cost savings relative to A. Conversely, selection of Measure B reveals an implicit value of life of at least $\$ 100,000$. Using this kind of reasoning it is possible, by examining past decisions for and against projects with potential safety effects, to place upper and lower bounds on implicit values of life and safety. Plainly, consistency in the treatment of accident effects in past decisions requires that such implicit values have broadly similar orders of magnitude. ${ }^{6}$ In fact, evidence from both the U.K. and U.S.A. indicates grossly inconsistent implicit values of life in past decisions affecting safety. In the U.K., for example $^{7}$ implicit values range from less than $£ 1,000$ per life (from a decision not to legislate for the child-proofing of drug containers) to more than $£ 20 \mathrm{~m}$. per life (in high-rise apartment safety standards). Similar results have beein obtained for the U.S.A. ${ }^{8}$ The sense in which this inconsistency implies allocative inefficiency can be seen most clearly by noting that a straightforward transference of resources from, for example, high rise apartment safety to the child-proofing of drug containers would, on balance, save lives at no additional resource cost overall. Thus, empirical evidence confirms the a priori expectation that leaving the assessment of safety effects to informal judgement is likely to lead to serious inconsistency and allocative inefficiency. There is no reason to suppose

6 There may, of course, be exceptional circumstances in which relatively high implicit values are warranted by considerations that over-ride consistency and allocative efficiency. For a discussion of such possibilities, see Linnerooth [1982].

7 See Card and Mooney [1977].

8 See Carlson [1963]. 
that decisions concerning preventive measures for natural disasters would be immune to such problems.

While we are dealing with the concept of implicit values of life and safety, it is worth noting that any decision for or against a project that has safety effects necessarily places an upper or lower bound on the relevant implicit value. Thus, anyone who argues that the explicit valuation of life or safety is infeasible, unwarranted or immoral, must nonetheless face the fact that however such decisions are taken, some form of implicit valuation is literally unavoidable.

\section{Safety standards and targets}

Next, consider the third possible way of taking account of safety effects in project appraisal - the use of safety standards or targets. While being an apparently simple and straightforward way of solving the problem, safety standards suffer from two very serious limitations. First, their use begs the vitally important question of the criteria by which such standards should be set. Second, there is the related problem that the use of safety standards takes no account of the cost of meeting such standards. Once again these factors are likely to lead to allocative inefficiency. To see how, consider the following simple but illuminating example.

Suppose that a particular country is vulnerable to the occurrence of two types of natural disaster, $\mathrm{A}$ and $\mathrm{B}$, each of which has, as its primary consequence, loss of human life. Currently, the expected loss of life over the next decade form from Type A disasters is 5,000 while the expected fatalities from Type B disasters over the same period is 20,000 . It has been estimated that the capital costs of reducing these fatalities to various levels are as follows :

Table 1

\begin{tabular}{|c|c|c|c|}
\hline \multicolumn{2}{|c|}{ TYPE A DISASTERS } & \multicolumn{2}{c|}{ TYPE B DISASTERS } \\
\hline $\begin{array}{c}\text { Expected } \\
\text { Fatalities }\end{array}$ & $\begin{array}{c}\text { Capital Cost } \\
\left(\$ \times 10^{6}\right)\end{array}$ & $\begin{array}{c}\text { Expected } \\
\text { Fatalities }\end{array}$ & $\begin{array}{c}\text { Capital Cost } \\
\left(\$ \times 10^{6}\right)\end{array}$ \\
\hline 5,000 & nil & 20,000 & nil \\
4,000 & 1 & 15,000 & 2 \\
3,000 & 2 & 10,000 & 5 \\
2,000 & 3 & 5,000 & 10 \\
1,000 & 5 & 4,000 & 25 \\
500 & 10 & 3,000 & 45 \\
100 & 20 & 2,000 & 82 \\
50 & 40 & 1,000 & 160 \\
20 & 10 & 500 & 200 \\
& & 100 & 500 \\
\hline
\end{tabular}


The country's government has to allocate its budget of $\$ 85 \times 10^{6}$ for disaster prevention between the two types of disaster and in the event decides to do so by the application of a uniforn safety standard which specifies that fatalities be reduced to 2,000 for each of the two types of natural disaster.

If we now consider the implicit value of avoidance of one fatality entailed by the policy with regard to Type $A$ disasters we find that this must be less than $\$ 2,000$ per fatality because the government is effectively unwilling to transfer $\$ 2 \times 10^{6}$ of its disaster budget to Type A disasters thereby reducing Type A fatalities from 2,000 to 1,000. However, by an analogous process of reasoning we discover that the implicit value of avoidance of one fatality reflected in the prevention expenditure for Type B disasters lies between $\$ 37,000$ and $\$ 78,000$ per fatality.

Clearly, then, the imposition of a uniform safety standard involves a serious inconsistency of implicit valuation of safety. Suppose, however, that the government could be persuaded to abandon its uniform safety standard and simply transfer $\$ 37 \times 10^{6}$ of its disaster budget from Type B prevention to Type A. To be sure, expected Type B fatalities would rise from 2,000 to 3,000 but expected Type A fatalities would fall from 2,000 to 50 implying a reduction in total fatalities from 4,000 to 3,050 - an overall saving of 950 lives.

The use of uniform safety standards and the consequent inconsistency of implicit valuation of safety can therefore be seen to cost the country 950 lives over the next decade. Notice that this would not be the case if the government were to apply a uniform valuation of safety rather than a uniform safety standard.

Of course it might be objected that the real justification for applying uniform safety standards lies in considerations of equity and fairness. A number of points can be made in relation to this objection. First, it has force only if equity is taken to over-ride efficiency as an objective in allocative decision-making whenever the two conflict. However, while equity is undoubtedly an important consideration, it is not usually taken to be lexicographically dominant over efficiency. Second, event if it is held to be of comparable or even greater importance than efficiency, it is not at all clear that in the above example equity would necessarily be synonymous with equalisation of the number of fatalities from the two types of disaster. Suppose that the disasters would affect two different regions within the country and that the population of the region affected by Type A disasters is very much smaller than that affected by Type B. Equalisation of expected fatalities would then imply far higher individual risks for the smaller region. Would that be equitable? Equally, suppose that the victims of the two types of disaster would be randomly drawn from the same population. Would a situation involving 50 fatalities from disaster Type A and 3,000 from Type B be inequitable?

\section{Cost-effectiveness analysis}

What of cost-effectiveness analysis? If it were the case that the overall disaster prevention budget was predetermined and if, in addition, the problem was simply to allocate this expenditure amongst competing schemes, each of which affected nothing but, say, the number of expected fatalities, then cost-effectiveness analysis would undoubtedly be the appropriate tool of analysis. One would simply rank preventive measures in terms 
of cost-effectiveness and then, starting with the most cost-effective measure, work through the list until the budget was exhausted. A little reflection, however, reveals two very serious limitations which together render cost-effectiveness analysis of severely limited use as a general solution to our problem. In the first place, cost-effectiveness analysis provides no indication of the appropriate size of the safety budget. Second, cost-effectiveness analysis ceases to provide an answer to a project-selection problem whenever mutually exclusive projects provide more than one kind of benefit, with the "mix" of benefits differing between projects. In such circumstances one requires some common unit in which to weigh or aggregate benefits and this is precisely what cost-effectiveness analysis (in marked contrast to cost-benefit analysis) does not do. To highlight this difficulty, consider a situation in which a budget of $\$ 10 \mathrm{~m}$. must be spent on one of two schemes, each of which precisely exhausts the budget but which would yield the following mixes of damage cost reduction and safety effects :

$\begin{array}{cccc} & \begin{array}{c}\text { Capital } \\ \text { Cost }\end{array} & \begin{array}{c}\text { Total Damage } \\ \text { Cost Reduction }\end{array} & \begin{array}{c}\text { Expected Serious } \\ \text { Injuries Avoided }\end{array} \\ \text { Scheme A } & \$ 10 \times 10^{6} & \$ 9,999,999 & 1 \\ \text { Scheme B } & \$ 10 \times 10^{6} & \$ 9,999,800 & 100\end{array}$

Given that the budget is predetermined, it might seem that cost-effectiveness analysis could be used to decide which scheme to adopt by comparing the net cost (capital cost minus damage cost reduction) per serious injury avoided. For Scheme A this would be $\$ 1$ while for Scheme B it would be $\$ 2$. Scheme A is, in this sense, more cost-effective than B. Should Scheme A therefore be adopted? Suffice it to note that anyone who recommends the adoption of $\mathrm{A}$ is effectively committed to the view that 99 additional serious injuries avoided under B are not worth the loss of $\$ 199$ of damage cost reduction. Surely few people would wish to take that position. Clearly, setting aside the alternatives already rejected, what is required in a decision such as this is an explicit valuation of injuries avoided in order to allow a direct comparison with capital costs and damage cost reduction. (Notice that in the particular example under consideration, an explicit value of avoidance of one serious injury of as little as $\$ 2.02$ would be enough to swing things in Scheme B's favour !)

Having said all this, it must be conceded that cost-effectiveness analysis does have a valuable rôle to play in ranking different design features of preventive measures when the sole effect of such features is to improve safety. It would clearly be of considerable value to know the relative cost-effectiveness of, for example, different kinds of medical facility or alternative temporary housing measures etc. in reducing fatalities following disasters. However, it should be stressed that once the most cost-effective safety features have been incorporated into the design of potential preventive measures, the final selection of measures - each typically offering a range of different kinds of safety effect as well as a range of benefits in addition to safety - cannot be handled by cost-effectiveness analysis and would appear to require some sort of explicit valuation of safety improvement. Accordingly, we turn to the fifth possible procedure for taking account of safety effects in the evaluation of preventive measures.

\section{The explicit costing of accidents and valuation of accident prevention}

The preceding argument suggests that if the achievement of an economically efficient allocation of scarce resources is a primary goal in the selection of preventive measures, 
then only by associating explicit costs with accidents and explicit values with the prevention of death and injury is there any real hope of achieving this goal. All of the other approaches discussed so far seem likely to lead to inconsistency and inefficiency characterised by a situation in which a straightforward re-allocation of resources, at no extra cost overall, would save lives and reduce injuries. The key question is then how such costs and values might be defined in principle and estimated in practice.

It is possible to identify at least six different methods that have been proposed for defining the cost of accidents or the value of accident-prevention. While all of the methods are, with appropriate modification, applicable to non-fatal as well as fatal accidents I shall, for the sake of clarity and simplicity, concentrate upon accidents involving precisely one fatality. The six approaches to the costing and valuation of accidents are :

(a) The "gross output" (or "human capital " approach) - in which the cost of an accident involving one fatality is treated as the sum of real resource costs (such as material damage, medical and police costs) and the discounted present value of the victim's future output. The value of the prevention of an accident is correspondingly defined as the avoided cost. In some variants of this approach, a significant sum is added to the output loss and resource costs to reflect the "pain, grief and suffering" of the accident victim and those who care for him or her.

Estimates of "gross output" costs and values are usually based on average output or earnings data together with appropriately estimated damage, medical and police costs.

(b) The "net output" approach - which differs from (a) only to the extent that the present value of the victim's future consumption is substracted from the gross output figure. An individual's net output - the difference between his gross output and future consumption - may be regarded as a measure of society's direct economic interest in his continued survival, though it should be stressed that the term " economic " is here being used in its very narrow, purely productive sense. Again, estimates are usually based on average output or earnings data net of per capita consumption.

(c) The "life-insurance" approach - in which the cost of an accident or the value of accident-prevention is directly related to the sums for which "typical " individuals are willing to insure their own lives (or limbs).

(d) The "court-award" approach - in which the sums awarded by the courts to the surviving dependents of those killed as a result either of crime or of negligence are treated as indicative of the cost that society associates with the accident or the value that it would have placed on its prevention.

(e) The "implicit public sector valuation" approach - in which an attempt is made to determine the costs and values that are implicitly placed on accident-prevention in safety legislation or in public sector decisions taken either in favour or against investment programmes that affect safety. Implicit costs and values are estimated along the lines described earlier in the paper.

(f) The "willingness-to-pay " approach - which is founded on the fundamental premise that allocative decision-making by governments or public sector bodies should reflect the interests and wishes of those individual citizens who will be affected by the decisions (this is, incidentally, the fundamental premise of conventional social cost-benefit analysis). Accordingly, the value of safety improvement is defined in terms 
of the amount that individuals are willing to pay for it, the cost of a deterioration in safety being defined analogously in terms of the amount people would require in compensation for the increased risk. More specifically, the value of a particular safety improvement is defined as the (possibly weighed ${ }^{9}$ ) aggregate of the amounts that people would individually be willing to pay for the (normally very small) reductions in risk afforded by the safety improvement. The cost of a deterioration in safety is similarly defined as an aggregate of required compensation. ${ }^{10}$

Estimation of willingness-to-pay based costs and values is far from straightforward. Basically three approaches have been used:" "revealed preference", "questionnaire" and "a priori restrictions".

In the revealed preference approach one attempts to obtain estimates by observing situations in which people actually do trade-off wealth or income for physical risk typically in labour markets for relatively risky occupations - while in the questionnaire approach a sample of individuals is asked more or less directly how much each would individually be willing to forfeit to effect various (small) reductions in their own or other people's risk. Each of these two approaches has its own particular strengths and weaknesses. The advantage of the revealed preference approach is that it generates costs and values based upon real choices : its principal disadvantage is that situations involving pure wealth/risk trade-offs are rather rare so that it is usually necessary to disentangle the effects of other factors such as time and inconvenience. In addition, the kind of situations in which wealth/risk trade-offs are most readily observable typically involve highly biased samples of individuals (no doubt steeple-jacks earn wages that carry a readily discernable risk premium but the risk attitudes of steeple-jacks are unlikely to be typical of those of the rest of the community). By contrast the questionnaire approach has the great advantage of allowing the researcher to "tailor" his survey instrument and sample to elicit precisely the kind of information that he requires. However the primary drawback of this approach is that it is based upon subjects' responses to hypothetical rather than actual choice situations.

The a priori restrictions approach is quite different from the previous two in that no attempt is made to enquire directly into wealth/risk trade-offs. Instead theoretical analysis - based on "reasonable" assumptions concerning individual preferences and attitudes to risk - is used to place a priori restrictions on the relationship between willingness-to-pay for physical risk reduction and income, age and other readily observable personal data. The results of this kind of analysis are of necessity rather imprecise, but it has proved possible to place plausible lower bounds on typical willingness to pay.

Given these six different methods of defining and estimating costs of accidents and values of accident prevention, two questions naturally arise :

9 A weighted aggregate would be relevant if one wished to take account of the distributional judgement that a benefit of $\$ 1$ to a poor person is, from a social point of view, "worth more " than $\$ 1$ to a rich person. For a discussion of the use of distributional weights in social cost-benefit analysis, see Weisbrod [1968].

${ }^{10}$ For a fuller discussion of the willingness-to-pay approach, see Jones-Lee [1976, 1982].

"For a summary of "revealed preference" and "questionnaire" estimates, see Blomquist [1982] and for an example of the "a priori restrictions" approach see Bergstrom [1982], Jones-Lee [1981] or Shepard and Zeckhauser [1982]. 
(a) Do the different methods yield significantly different numerical costs and values?

(b) To the extent that differentials do emerge, will such differences matter for project appraisal ? That is, will project rankings be significantly affected by the substitution of one for another of the costing/valuation methods?

Only if both of these questions are answered in the affirmative is it worth agonising over the choice of an explicit costing and valuation method and devoting scarce resources to the generation and refinement of estimates.

Ideally, the question of whether or not the various costing and valuation methods yield significantly different numerical costs and values should be answered with specific reference to estimates derived directly from particular countries. However such estimates are currently simply not available for the majority of countries and in the case of willingness-to-pay based costs and values, would require fairly extensive basic data collection before any attempt at estimation could be made. One can, however, get some sort of feel for the differences that might emerge by considering estimates derived for a few developed countries. While absolute (and indeed relative) magnitudes will almost certainly differ between the developed and developing country cases, it would nonetheless seem improbable that the different methods would yield, for example, very substantial differences in developed countries but insignificant differences in developing countries. Accordingly some developed country estimates of the cost of a " statistical " 12 fatality and value of avoidance of a statistical fatality are summarised in the table below. In all cases

Table 2

\begin{tabular}{|c|c|c|}
\hline & Valuation/Costing Method & $\begin{array}{l}\text { Cost/Value of } \\
\text { one "statistical " } \\
\text { fatality }\end{array}$ \\
\hline (i) & $\begin{array}{l}\text { Gross output: } \\
\text { (a) including subjective component (Dawson [1971]) } \\
\text { (b) including subjective component but increased } 50 \% \text { and } \\
\text { with reduced discount rate applied (U.K. Department } \\
\text { of Transport [1978]) }\end{array}$ & $\$ 225,000$ \\
\hline (ii) & $\begin{array}{l}\text { Net output: } \\
\text { (a) excluding subjective component (Reynolds [1956]) } \\
\text { (b) including subjective component (Dawson [1969]) }\end{array}$ & $\begin{array}{l}\$ 25,000 \\
\$ 76,000\end{array}$ \\
\hline (iii) & Life-insurance basis : Fromm [1965] & $\$ 930,000$ \\
\hline (iv) & $\begin{array}{l}\text { Court-awards basis: } \\
\text { (a) Abraham and Thedié [1960] } \\
\text { (b) Shepherd [1974] }\end{array}$ & $\begin{array}{r}\$ 83,000 \\
\$ 1,000,000\end{array}$ \\
\hline $\begin{array}{l}\text { (v) } \\
\text { (vi) }\end{array}$ & $\begin{array}{l}\text { Implicit public sector valuation: } \\
\text { Card and Mooney [1977] } \\
\text { Willingness-to-pay approach: }\end{array}$ & $\begin{array}{l}\$ 3,000-\$ 60 \times 10^{6} \\
\$ 2,100,000\end{array}$ \\
\hline
\end{tabular}

12 For example, the exposure of $10^{6}$ people to an incremental independent risk of death of $10^{-6}$ each, is said to involve one "statistical" fatality. 
except willingness-to-pay, sources are cited. The willingness-to-pay figure is a point estimate based on a number of different studies ${ }^{13}$ and is intended merely to give the general order of magnitude that tends to emerge from such studies. All costs and values are in \$ U.S. at 1979 prices.

Given these estimates, there can be little doubt that the different methods for defining and estimating costs of accidents and values of accident prevention do indeed yield very different numerical magnitudes. It should be stressed that these estimates are for developed countries (specifically the U.K., U.S.A. and France) but they would seem to represent prima facie evidence that, were comparable estimates available for developing countries, they would tell a broadly similar story. The first of our questions appears, then, to be (tentatively) answered in the affirmative.

Next, we turn to the question of whether or not such differences matter. To answer this question in the context of preventive measures for natural disasters one would ideally want to apply a sensitivity analysis to the selection of preventive options. To this author's knowledge no such analyses have so far been undertaken. Sensitivity tests have, however, been conducted for the case of transport project selection (notably in Leitch [1977] and Hills and Jones-Lee [1981]). The results of these sensitivity analyses, while not directly relevant to the case of natural disasters, nonetheless suggest the way things might turn out in that case. In a nutshell, variation of accident costs and values of accident prevention over a fraction of the range covered in Table 2 turns out to have a substantial effect both on benefit/cost ratios and, more significantly, on project rankings in both of the studies cited. Again this seems to constitute prima facie evidence that, far from being a matter of subsidiary importance, the size of accident costs or values of accident-prevention can (and, in most cases, almost certainly would) have a marked effect on the selection of competing preventive options. In short, it would appear that the issue of the "appropriate" cost to associate with particular types of accidents - or values to place upon their avoidance - is not one that can legitimately be ignored on the grounds that accident costs and values have little overall importance in project-appraisal : the simple message of the sensitivity tests referred to above is that such costs and values are potentially very important indeed.

Given that explicit costing of accidents and valuation of accident prevention would seem to be essential if allocative inefficiency is to be avoided and since it would appear to matter which of the six explicit costing and valuation methods described above is adopted, the question is then which of these methods is the most appropriate for the selection of preventive measures for natural disasters.

Ultimately, the answer to this question depends upon the social, political and economic objectives of the agency that will employ the costs and values in the selection of preventive options. Much can be said on this question and the reader who is interested in a fuller discussion of the relationship between objectives and costing/valuation methods is referred to Hills and Jones-Lee [1981]. For present purposes suffice it to note that whatever objectives are, in the event, pursued by any agency, these will almost certainly include as significant components either maximisation of some index of national output

${ }^{13}$ See Hills and Jones-Lee [1981], Appendix II. 
for the country under consideration or maximisation of a more widely-cast index of social welfare, the latter having as its most common concrete application, a conventional social cost-benefit analysis. If this is the case, then only two of the accident costing/valuation methods discussed above have any direct relevance : the gross output (or human capital) approach for national output goals and the willingness-to-pay approach for social-welfare goals. ${ }^{14}$ Before attempting to make a final selection between these alternatives it will be useful to consider the last of the six different methods for evaluating preventive measures, namely decision analysis.

\section{The decision analysis approach}

This approach to the evaluation of projects that have expected effects on the safety of life has been most fully developed in a sequence of papers by Keeney [1980 a, $1908 \mathrm{~b}$, and 1982]. Basically, the idea is first to identify the key consequences of potential accidents or disasters (e.g. number of lives lost, number of non-fatal injuries, percentage reduction in G.N.P., etc.) and then to define a Von Neumann/Morgenstern utility function ${ }^{15}$ whose arguments are the relevant consequences. This multi-attribute "organisational " utility function is construed as being essentially that of the relevant decision maker (or decision making group) and therefore ultimately reflects the value judgements of the decision maker concerning tradeoffs between different consequences and choices between different probability distributions of particular consequences. In [1980 b] and [1982] Keeney's primary purpose is to demonstrate the inherent incompatibility of three fundamental value judgements that most people would probably wish the organisational utility function to reflect, namely (i) the desirability of minimising expected loss of life ; (ii) the desirability of an equitable distribution of risk of loss of life amongst members of the population ; and, (iii) the desirability of avoiding catastrophes (i.e. loss of large numbers of lives). Keeney shows that the first value judgement entails linearity of the utility function in number of lives lost, the second strict convexity and the third strict concavity - plainly mutually incompatible requirements. In [1980 a] the objective is more closely orientated to outlining a procedure by which the organisational utility function could, in principle, actually be estimated for a particular decision maker.

14 It seems clear that both the gross output and willingness-to-pay definitions of accident costs/values should take account of the extent of unemployment. An unemployed individual will, for example, make no contribution to gross output during the period of his unemployment. Similarly, to the extent that individual willingness to pay for safety is dependent on income, this too will be affected by whether or not the individual is employed. Perhaps the most straightforward way of taking account of unemployment effects is to estimate two kinds of costs of accidents/value of avoidance of accidents : one conditional on the typical individual being in employment, $v_{e}$, and the other conditional on the typical individual being unemployed, $v_{\mu}$. Given the ex ante anonymity of victims of future road accidents it would seem appropriate to define a "shadow" cost of accident/value of avoidance of accidents in terms of the expected cost or value, that is with unemployment rate $u$, as $(1-u) v_{e}+u v_{u}$.

15 Provided that an individual's preferences over options with uncertain consequences are sufficiently well-behaved (or " coherent "), it will be possible to define a cardinal utility function on the consequences such that the preference ordering over the options is represented or " mirrored " by the mathematical expectation of utility. See Von Neumann and Morgenstern [1947] or Savage [1954]. 
Taken at face value, Keeney's organisational utility function would seem to represent a potentially effective alternative to the estimation and use of explicit costs of accidents and values of accident prevention. Certainly it's use would avoid the problems of inconsistency and inefficiency that beset some of the other approaches to the evaluation of preventive measures. Unfortunately this approach suffers from certain essentially practical limitations. In the first place it seems rather unlikely that the majority of decision makers would be willing to conduct the kind of thought experiments that are required in order to estimate parameters of the utility function (or would, at least, be unwilling to regard the results of such experiments as a conclusive and immutable representation of their views on safety, etc.). Second, even if the estimation problem could be overcome, it seems improbable that decision makers would then be willing to allow decisions to be determined solely with reference to the mathematical expectation of the estimated utility function, effectively relinquishing their active decision making role. Thirdly, there is nothing inherent in Keeney's approach that suggests to the decision maker how or by what criteria he ought to trade-off life saving against other consequences such as avoidance of material damage, etc., though he certainly has to make up his mind about such trade-offs before the organisational utility function can be estimated. In other words Keeney's approach begs precisely the question that lies at the heart of explicit costing and valuation approach and simply returns the question unanswered (and indeed unilluminated) to the decision maker. ${ }^{16}$

Nonetheless, the decision analysis approach does have certain advantages as an aid to organising thought about explicit costs of accidents and values of accident prevention, especially when one is dealing with the possible loss of large numbers of lives. An aspect of Keeney's analysis that is particularly useful in this respect is his concept of a " disutility of lives lost function" (see especially Keeney [1980 a]) and his demonstration that the "shape" of such a function (specifically, its linearity, concavity of convexity) has direct implications for the relative evaluation of loss of "statistical "life (the exposure of a number of individuals to independent risks of death), the loss of " anonymous " life (the certain loss of life of as yet unidentified individuals) and "catastrophes" (typically, low probabilities of the loss of large numbers of lives). For example, suppose that the cost, $c$, of the loss of one statistical life - say the exposure of $10^{4}$ people to independent incremental probabilities of death of $10^{-4}$ each - has been estimated by whatever means (e.g. on a gross output or willingness-to-pay basis). Will it then be appropriate to treat the incremental probability of $10^{-4}$ of a catastrophe involving the loss of $10^{4}$ lives as also having a cost $c$ ? (Notice that in both cases the expected loss of life is the same, i.e. one.) It turns out that the matter can be unambiguously resolved by reference to the form of Keeney's disutility of lives lost function. In fact, only if this function is linear will it be appropriate to treat the catastrophe risk as equivalent to the loss of statistical life : if the function is concave then the cost of the catastrophe risk will be more than $c$ and if the function is convex it will be less than $c$. Furthermore, if the disutility of lives lost function is fully specified then it would be possible to determine the number of statistical lives that would be equivalent to a particular catastrophe risk. Thus, for example, it would be possible to determine the probability, $10^{-x}$, such that the exposure of $10^{4}$ people to independent incremental risks of $10^{-x}$ each would be precisely equivalent to the incremental probability

\footnotetext{
16 For further comments on Keeney [1982] see Loubergé [1982].
} 
of $10^{-4}$ of a catastrophe involving $10^{4}$ deaths (specifically, $x$ would be such that the two risks had precisely the same mathematical expectation of disutility). It follows that the catastrophe risk is equivalent to the loss of approximately $10^{(4-x)}$ statistical lives so that if the cost of the loss of one statistical life is $c$, then the cost of the catastrophe would be approximately $10^{(4-x)} c$, with, of course, $x \lesseqgtr 4$ as the utility function is concave, linear or convex. ${ }^{17}$

Clearly, then, armed with (a) an estimate of the value of statistical life (or cost of loss of statistical life) and (b) an estimate of the relevant Keeney-type disutility of lives lost function, together with their counterparts for non-fatal injury, a decision maker or decision making group would be fully equipped to make the kind of trade-off decisions required for an efficient and consistent evaluation of preventive measures. This is precisely the sense in which it was suggested earlier that a blend of explicit costing/valuation and a decision-theory approach would represent the most effective solution to the problem addressed in this paper. There remains, however, the question of precisely how explicit costs of accidents and values of accident prevention are to be defined and estimated and how a disutility of lives lost function might be specified.

As far as the costs of accidents and values of accident prevention are concerned, it was suggested in the previous section that the choice of definition would almost certainly lie between the gross output (or human capital) approach and the willingness-to-pay approach, the final selection depending ultimately upon the objectives of the decision making agency. For what it is worth, it is the author's experience that the majority of decision makers in public sector bodies or aid-giving agencies who have given thought to this question conclude that the willingness-to-pay definition is in principle superior but beset by fairly severe estimation problems. Thus for example, while the U.K. Department of Transport is actively engaged in attempts to estimate willingness-to-pay based costs and values for road accidents, a recent World Bank Symposium reached the conclusion that while the willingness-to-pay approach is ideally to be preferred, nonetheless estimation problems dictate that the gross output approach will have to be used for the time being, if only as a "second best" means of placing a lower bound on willingness-to-pay. ${ }^{18}$

Estimation of a disutility of lives lost functions presents rather different, but equally difficult problems. To be sure, one could attempt such estimation along the lines suggested in Keeney [1980 a], but this would probably run into the kind of difficulties mentioned above (e.g. unwillingness of decision makers to conduct the relevant thought-experiments and/or unwillingness to regard the results of such experiments as "really credible"). Perhaps the most that can be hoped for at this stage is that decision makers should organise their thinking with reference to the concept of such a function, merely specifying whether they think that it should be linear, concave or convex and possibly going so far as to decide, if non-linear, whether it should be strongly so. This may be an over-pessimistic view

17 This result is an approximation (a) to the extent that individual willingness to pay will tend to vary non-linearly with the size of increments in individual risk and (b) to the extent that the disutility of lives lost function is also non-linear.

18 The conditions under which human capital may be taken to represent a lower bound to the willingness to pay based value of statistical life are discussed in Conley [1976], Jones-Lee [1980, 1981], Bergstrom [1982], Dehez and Drèze [1982] and Shepard and Zeckhauser [1982]. 
and it remains to be seen whether or not decision makers would be willing to go further than this.

\section{Summary and recommendations}

The main arguments of this paper are the following.

(a) That the enormity of the potential consequences of natural disasters and the fact of resource scarcity require that limited budgets for disaster prevention and mitigation be expended as efficiently and effectively as possible.

(b) That the principal difficulty in devising procedures for the effective allocation of prevention budgets arises from the diversity of the potential consequences of natural disasters so that reductions in loss of life, injury and suffering must ultimately be weighed against each other and also against reductions in material damage and other effects on G.N.P.

(c) That of the six different approaches that might be adopted for the evaluation of preventive measures, only two offer any serious hope of avoiding inconsistency and inefficiency in the evaluation of preventive measures. These are :

(i) the explicit costing of loss of life, injury, etc. and the explicit valuation of life saving, with costs and values then being used to aggregate safety effects with material damage effects in a conventional cost-benefit analysis, and

(ii) the decision analysis approach involving a more or less fully-specified "organisational " utility function.

(d) That of the various different definitions of costs of accidents/values of accident prevention, only the so-called gross output and willingness-to-pay definitions are likely to square with the kind of economic and social objectives typically pursued by the majority of public sector or aid-agency decision makers and that of these two definitions it is probably willingness-to-pay that will tend to be favoured, at least in principle. This observation has, however, to be tempered by an appreciation of the substantial difficulties of empirical estimation in the case of the willingness-to-pay approach.

(e) That provided costs of accidents and values of accident prevention are defined and estimated for the case of loss of statistical life or statistical injury, then the corresponding costs of loss of life and injury in catastrophes could in principle be estimated as a fraction or multiple of the cost of loss of statistical life using a Keeney-type disutility of lives lost (or injury) function.

Consequently, it is recommended that preventive measures for natural disasters should be evaluated by a hybrid of cost-benefit and decision analysis, with monetary costs of fatalities and injuries (or monetary values of life-saving, etc.) defined and estimated with reference to statistical lives and injuries - probably on a willingness-to-pay basis. The corresponding costs of loss of life and injury in disasters or catastrophes should then be derived from these statistical costs and values on the basis of an organisational " disutility of lives lost" (or injury) function. The precision that can be expected of estimates of the value of statistical life and the disutility of lives lost function is, however, an open question and may well be a fruitful subject for further research and investigation. 


\section{REFERENCES}

ABRAHAM, C., and THEDIÉ, J. [1960]: “Le Prix d'une Vie Humaine dans Les Décisions Economiques ", Revue Française de Recherche Opérationnelle.

BERGSTROM, T. C. [1982] : "When Is A Man's Life Worth More Than His Human Capital ", in : Jones-Lee, M. W. (ed) [1982] The Value of Life and Safety: Proceedings of a Conference Held by the "Geneva Association" (North Holland, Amsterdam).

BLOMQUIST, G. [1982] : “Estimating the Value of Life and Safety: Recent Developments ”, in : Jones-Lee [1982] op. cit.

CARD, W. I., and MOONEY, G. H. [1977] : "What is the Monetary Value of a Human Life?", British Medical Journal (December).

CARLSON, J. W. [1963] : Evaluating Life Saving, Ph.D. Dissertation (Harvard University).

CONLEY, B. C. [1976] : "The Value of Human Life in the Demand for Safety ", American Economic Review (March).

DAWSON, R. F. F. [1967] : Cost of Road Accidents in Great Britain (Road Research Laboratory, Ministry of Transport, London).

DAWSON, R. F. F. [1971] : Current Costs of Road Accidents in Great Britain (Road Research Laboratory, Department of the Environment, London).

DEHEZ, P., and DRĖZE, J. H. [1982] : “ State-Dependent Utility, The Demand for Insurance and the Value of Safety" in: Jones-Lee [1982] op. cit.

FROMM, G. [1965] : “Civil Aviation Expenditures", in : Dorfman, R. (ed) Measuring Benefits of Government Investments (Brookings, Washington).

HILLS, P. J., and JONES-LEE, M. W. [1981] : The Costs of Traffic Accidents and the Valuation of Accident Prevention in Less Developed Countries (Report to World Bank. Forthcoming as World Bank Staff Working Paper).

JONES-LEE, M. W. [1976]: The Value of Life: An Economic Analysis (Martin Robertson, London and Chicago University Press).

JONES-LEE, M.W. [1980]: "Human Capital, Risk Aversion and the Value of Life", in: Currie, D. A., and Peters, W. (eds) Contemporary Economic Analysis, Vol. 2 (Croom Helm, London).

JONES-LEE, M. W. [1981] : “The Value of Non-Marginal Variations in Physical Risk", in : Currie, D., Peel, D., and Peters, W. (eds) Microeconomic Analysis (Croom Helm, London).

JONES-LEE, M. W. [1982] : Ed. The Value of Life and Safety : Proceedings of a Conference Held By The "Geneva Association" (North Holland, Amsterdam).

KEENEY, R. L. [1980 a]: “Evaluating Alternatives Involving Potential Fatalities", Operations Research (January/February).

KEENEY, R. L. [1980 b] : “Equity and Public Risk”, Operations Research (May/June).

KEENEY, R. L. [1982] : "Evaluating Mortality Risks From An Organisational Perspective ”, in : Jones-Lee [1982] op. cit.

LAYARD, R. [1972] : Ed. Cost Benefit Analysis (Penguin, Middlesex).

LEITCH, G. [1978] : Report of the Advisory Committee on Trunk Road Assessment (H.M.S.O., London).

LINNEROOTH, J. [1982] : “Murdering Statistical Lives... ?”, in : Jones-Lee [1982] op. cit. 
LOUBERGÉ, H. [1982]: “Comments on “Evaluating Mortality Risks from an Organisational Perspective " in : Jones-Lee [1982] op. cit.

REYNOLDS, D. J. [1956] : “ The Cost of Road Accidents ”, Journal of the Royal Statistical Society.

SHEPARD, D. S., and ZECKHAUSER, R. J. : " Life-Cycle Consumption and Willingness To Pay for Increased Survival " in : Jones-Lee [1982] op. cit.

SHEPHERD, J. G. [1974] : The Application of Cost-Benefit Analysis to Problems of Radiological Control, Technical Note RL3/74 (MAFF Fisheries Radiobiological Laboratory, Lowestoft, England).

SAVAGE, L. J. [1954] : The Foundations of Statistics (Wiley, New York).

SLOVIC, P., FISCHHOFF, B., and LICHTENSTEIN, S. [1980] : "Facts and Fears : Understanding Perceived Risk", in : Schwing, R. C., and Albers, W. A. (eds) Societal Risk Assessment: How Safe is Safe Enough? (Plenum Press, New York).

SUGDEN, R., and WILLIAMS, A. [1978] : The Principles of Practical Cost Benefit Analysis (Oxford University Press, Oxford).

U.K. DEPARTMENT OF TRANSPORT [1979] : Highway Economics Note No. I (London, December).

UNITED NATIONS [1979]: Disaster Prevention and Mitigation: A Compendium of Current Knowledge (New York).

VON NEUMANN, J., and MORGESTERN, O. [1947] : Theory of Games and Economic Behavior (Princeton University Press).

WEISBROD, B. A. [1968]: "Income Redistribution Effects and Benefit-Cost Analysis", in: Chase, S. B. (ed) Problems in Public Expenditure Analysis (Brookings, Washington). 